\title{
Development of a Robotic Arm for Automated Harvesting of Asparagus
}

\author{
Yuki Funami, Shinji Kawakura, and Kotaro Tadano
}

\begin{abstract}
We designed and developed an original arm-robot system that harvests asparagus in both outdoor and indoor agricultural fields. Using the system, we carried out harvesting work automatically with input data related to asparagus vegetation in restricted settings. The developed fixed-site (nonwheeled) robot can reach out its arm to a stem of asparagus from a passage between two ridges on cultivated farmland without touching non-target stems or requiring changes to the farm conditions. Additionally, the hand at the tip of the arm stably grasps, cuts, harvests, and throws the stem it into a specific bag made for the gathering of agricultural crops. In mechanical terms, our originally developed robot arm has four degrees of freedom and is driven by motors. It harvests target asparagus stems without coming into contact with other objects in an agricultural setting, and the hand using the linkage mechanism of a pneumatic cylinder driven by air pressure, can hold the stem firmly and cut it. Our repetitive verification experiments showed that the mechanism is sufficiently accurate. The present study confirmed the robot arm system could be used for automatically harvesting asparagus, and the system was endorsed by several farmers. Moreover, we carried out experiments of harvesting asparagus on actual outdoor land and successfully harvested three stems sequentially under the condition that the operator obtained the positional coordinates earlier.
\end{abstract}

Index Terms - automatic cropping; asparagus; robot arm; pneumatically control.

\section{INTRODUCTION}

The production of asparagus (A. asparagus officinalis, including A. schoberioides and A. cochinchinensis) is generally highly profitable and has been increasing in volume. Furthermore, there is a desire to increase the production of asparagus around the world. Meanwhile, workers suffer long-term fatigue because they need to stoop when harvesting asparagus and because a semi-crouching posture makes harvesting work difficult especially for elderly workers.

There has thus been a call for technology that reduces the load of labor, especially automation of the harvesting of asparagus, in recent years. Managers and workers in such greenhouses have been urged to approach and harvest asparagus shoots ready for harvest without touching the asparagus, especially in robot-based automatic harvesting.

We are therefore developing a robot system that automatically harvests (target) asparagus that is suitable for harvest without touching the (non-target) asparagus that is not suitable for harvest. The system holds a stem for harvest appropriately, cuts the stem, and gathers the harvested asparagus.

Past achievements in technical fields are the development of various automatic planting robots, harvesting robots, monitoring and sensing robots, and integrated, multi-purpose robots [1]-[42].
In light of the past promising achievements, we consider that three problems remain when diverse harvesting systems are introduced to non-specific agricultural fields in which asparagus is grown: 1) harvesting systems cannot approach asparagus shoots from the upper side, 2) harvesting systems must be driven without damaging shoots that are not the target of the harvest, and 3) agricultural workers have to prepare farmland so that the system operates well. Farmhouses have been pointing the aforementioned 1) - 3) requirements of the improvements, yet they face difficulties relating to introductory costs and the burden of preparing the land to optimize the harvest. Farmers therefore wish to use systems that do not require special handling, and highperformance automatic asparagus-harvesting robots have not been used in practice. The present work develops a robotarm-based system that can harvest asparagus in a narrow space between two ridges (or furrows or rows) without touching non-target stems and without requiring changes to farm conditions, based on the abovementioned points. The fundamental actions of the system are 1) moving the robot arm to the target asparagus, 2) holding the stem firmly, 3) cutting the asparagus, and 4) throwing (dumping) the asparagus into a bag.

\section{MATERIAL AND METHOD / EXPERIMENTAL}

\section{A. System architecture}

This section describes the design concept of the system. The aim of the study is to develop an integrated system that harvests asparagus on cultivated farmland where stalks of asparagus grow, without changing the condition of the fields. This requires the system to 1) approach a target stem from the passage between ridges without touching the mesh net on the upper side of the asparagus with a directly acting (prismatic, straight-line movement) mechanism, 2) harvest only the appropriate, target asparagus shoots without touching nontarget shoots (i.e., non-matured and damaged shoots), and 3) holding and cutting the asparagus stem without damaging it. Because the arm itself needs to be sufficiently small and contained within the width of the passage, we adopted a many-stage structure. Moreover, we allowed the hand part of the arm to rotate in the yaw direction to bypass (avoid) the non-target asparagus. We decided the speed through discussion with the farmhouse and from personal experience. As a result of discussion with farmers, we set the working efficiency so as to harvest $90 \%$ of asparagus (because, for several reasons, $100 \%$ harvesting is unrealistic and impossible in general) in 40 acres of non-specific farmland on one day; the speed was thus set to less than 20 seconds per the harvesting of one stem through the study. The robot arm was designed to have four joints (joints $\mathrm{J} 1$ to $\mathrm{J} 4$ ) according to the abovementioned design concepts. Figure 1 illustrates the 
directions of joint movements. We set joints $\mathrm{J} 1$ and $\mathrm{J} 3$ on the arm to move linearly, allowing the arm to approach the asparagus from a trough. Furthermore, joints $\mathrm{J} 2$ and $\mathrm{J} 4$ rotate to the yaw direction to bypass non-target asparagus stems. We summarize the ranges of motions of all joints. We set the stroke range of joint $\mathrm{J} 1$ as $300 \mathrm{~mm}$ considering the accumulating motion for the harvests into a specific way; the $300-\mathrm{mm}$ range provided a sufficient margin after taking future corrections, extensions, and unexpected failures into consideration. Joint $\mathrm{J} 2$ rotated within the range of $\pm 90^{\circ}$. Joint J3 had a stroke range of $900 \mathrm{~mm}$ on the basis of the width of common passages of farmland. Furthermore, for compactness, we adopted a two-step structure, with the stroke range of each part being $450 \mathrm{~mm}$. The wrist joint $\mathrm{J} 4$ had a range of rotation of $\pm 90^{\circ}$, allowing the arm to move to the upper side of the basket, when joint $\mathrm{J} 2$ rotated by $90^{\circ}$ from the standard (default) posture (Fig. 2), because the robot arm must not come into contact with the basket. The height of the basket was set at $100 \mathrm{~mm}$ from the ground according to discussions held with the farmhouse.

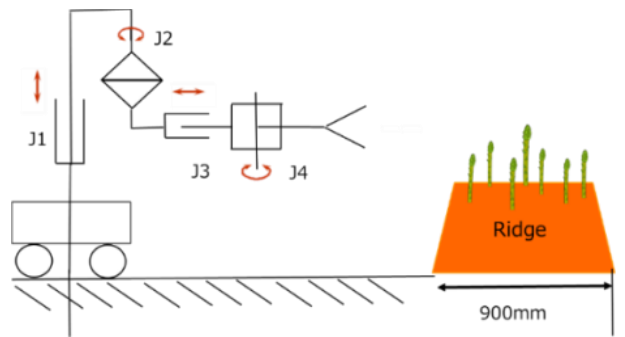

Fig. 1. Diagram of joints of the developed arm.

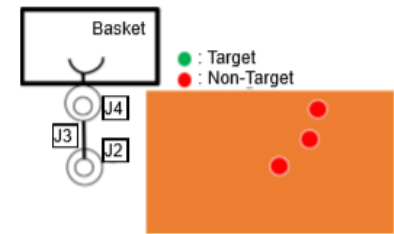

(a) Start position settings (after $0 \mathrm{~s}$ )

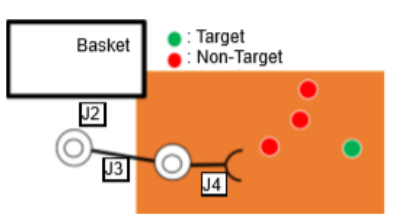

(b) Lifting of joint $\mathrm{J} 1$ and rotation of joint $\mathrm{J} 2$ (after $5 \mathrm{~s}$ )

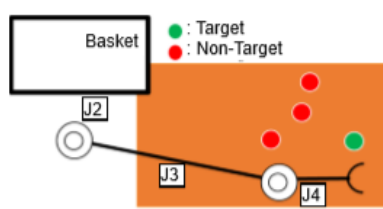

(c) Extension of joint $\mathrm{J} 3$ (after $7.5 \mathrm{~s}$ )

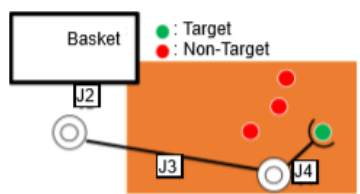

(d) Rotation and holding and cutting of joint $\mathrm{J} 4$ (after $10.0 \mathrm{~s}$ )
Fig. 2 concretely describe concerning the system's movements below, we considered a series of operations through which one asparagus stem is harvested in 20.0 seconds. In the beginning, we moved he arm located on just upper side of the basket, and descended e arm to the height of a target asparagus. 1) We lowered the arm from the upper side of the basket to the height of the target asparagus. 2) We simultaneously rotated joints $\mathrm{J} 1$ and $\mathrm{J} 3$ to their target angles. The system takes 5.0 seconds to conduct the two steps. In steps 1) and 2), we encountered difficulties in realizing a high-speed operation. Moreover, almost all the mass of the arm loaded the joint $\mathrm{J} 1$ in rising and descending movements. We therefore used a high-ratio gear mechanism. We thus consider a time span of 5.0 seconds to be appropriate. 3) We extended joint $\mathrm{J} 3$ to the middle of the target position (which took 2.5 seconds). 4) While conducting step 3), we began moving joint $\mathrm{J} 4$ to the target asparagus while bypassing nontarget objects (1.5 seconds). 5) After reaching the asparagus, the arm held and cut the asparagus (2.0 seconds). 6) In the reverse procedure, we began rotating joint $\mathrm{J} 4$ and retracting joint J3 (1.5 seconds). 7) We waited for joint J3 to finish retracting ( 2.5 seconds). 8 ) We adjusted the height of the hand through the control of joint $\mathrm{J} 1$, began rotating joint $\mathrm{J} 2$, and moved the arm toward the basket (5.0 seconds). In steps 3 ) to 8), through operations without rising and descending movements of the arm, we could increase the speed and shorten the duration of each step. 9) We finally dropped the asparagus into the basket ( 1.0 seconds).

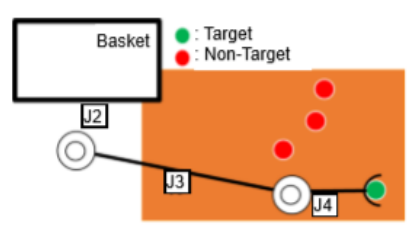

(e) Rotation of joint J4 (after $11.5 \mathrm{~s}$ )

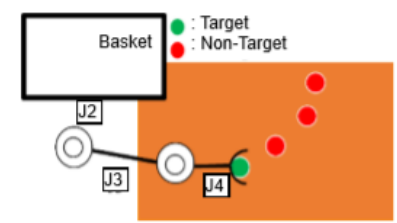

(f) Retraction of joint J3 (after $14.0 \mathrm{~s}$ )

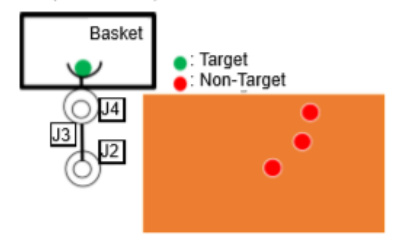

(g) Lifting of joint $\mathrm{J} 1$ and rotation of joint $\mathrm{J} 2$ (after 20.0 s)

Fig. 2 Motions of the robotic arm. 
We designed the robot arm according to the concepts mentioned earlier (Fig. 2). Joints J1 to J4 are shown in Figs. 3-8 while the motors and encoders used are summarized.
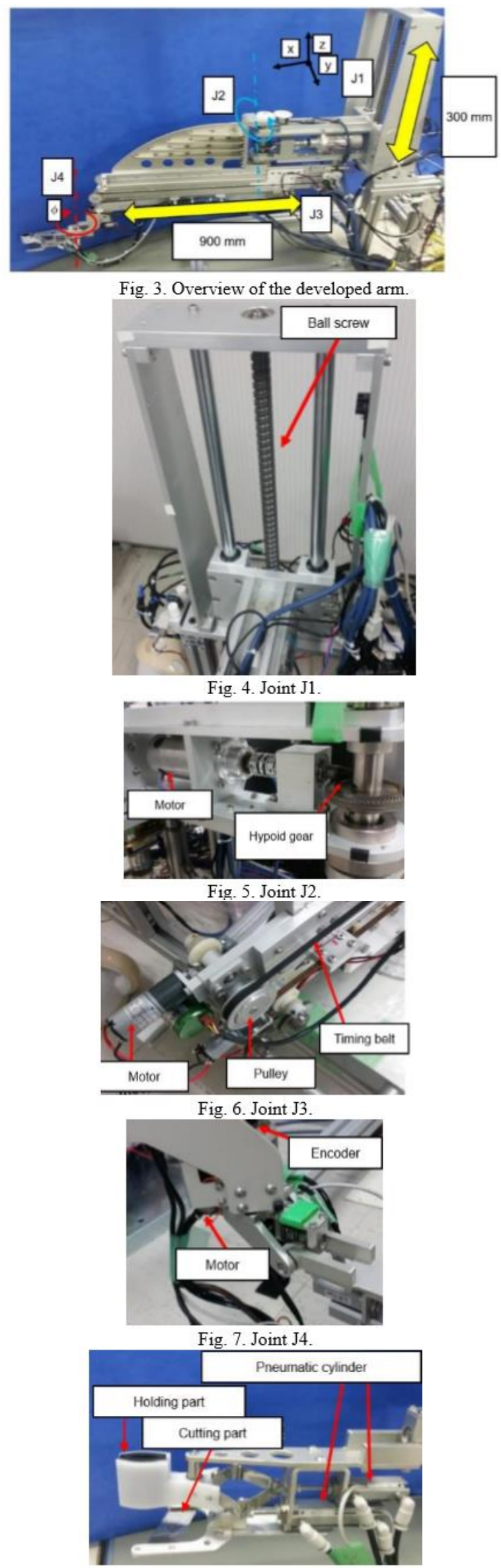

Fig. 8. Hand part.
For joint J1, we adopted a ball-screw-based system as the rising and falling mechanism of the arm to realize a high torque, and connected encoders with motors using gears to measure the rotational displacement (Figs. 3 and 4). We adopted motors including brakes so that the arm does not lower under gravity. Joint J2 outputs a comparatively large torque in limited space using a hypoid gear (Figs. 3 and 5). We connected an encoder with a motor using a gear and measured the rotational displacement. For joint J3, the rotational movement of the motor was converted to linear movement using a pulley and timing belt (Figs. 3 and 6). We connected the encoders with motors using a gear and measured the rotational displacement. For joint J4, we transmitted the power and moved a motor rotationally using a gear (Figs. 3 and 7) and connected the encoder with the motor using the gear, and we measured the rotational displacement. We developed the hand part at the end of the arm to be lightweight because it was operated by an airpressure driving system (Fig. 8). The hand was designed for later maintenance and not to damage the asparagus in the process of cutting. The hand could hold asparagus stems with the straight-line motion of a pneumatic cylinder converted to rotational motion by the linkage mechanism. Additionally, another pneumatic cylinder pushed the cutter out simultaneously, and target operations were thus realized. Furthermore, we used a precise air cylinder, electromagnetic valve, compressor, and relay circuit (Fig. 9-10).

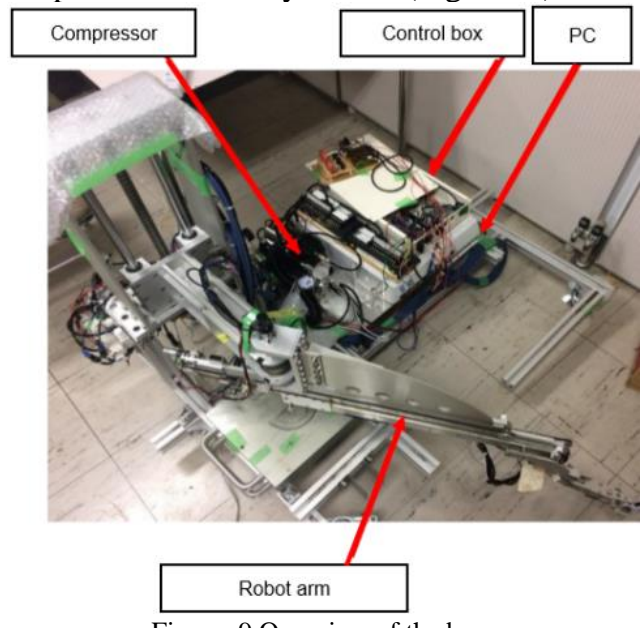

Figure. 9 Overview of the base

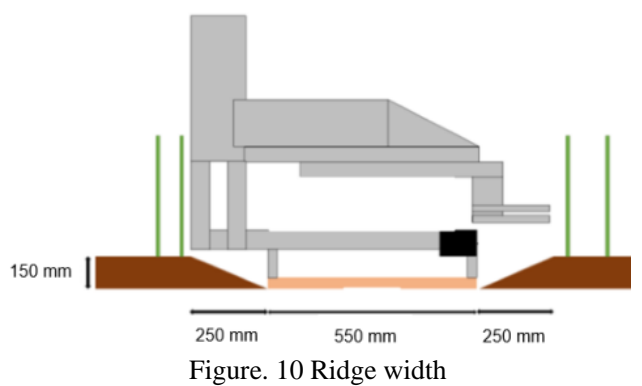

\section{B. Motion control system}

This section explains our automatic motion control system for asparagus harvesting with the robot arm. The system is schematically presented in Fig. 11 and comprises the main part of the arm, a control box, and a personal computer. We attached the personal computer and control box to the backside of a common cart, attached a compressor, and carried the cart to our experimental fields, which were actual cultivated fields. In the upper space of the control box, there were motor drivers (ESCON36/2 DC, Maxon Motor 
Inc., Japan) and a power supply module for driving the motor drivers (Fig. 12). The motor drivers were sufficiently small to sheathe in several positions and output current of up to $2 \mathrm{~A}$. We installed Ubuntu version 14.04 as the operating system of the control computer. Moreover, we changed it into real-time (RT) Linux for RT manipulation by including a real-time application interface (RTAI) and set the length of the control cycle as $1 \mathrm{~ms}$, and then inserted an add-in board into the peripheral component interconnect (PCI) slot of the personal computer for control. We added an input and output function by inserting two extender boards (add-in boards) into a PCI slot on the aforementioned control personal computer. The extender boards were an AD converter board (16 channels, PCI-320416, Interface Inc., Japan) and a counter board (four channels, CNT32-4M, CONTEC Inc., Japan). A block diagram of the control is presented in Fig. 13. We solved equations relating to the inverse kinematics and computed the target angle data for each joint from the target positioning data of the robot arm, and we thereby controlled the position of the arm using proportional and differential control methodology for each joint.

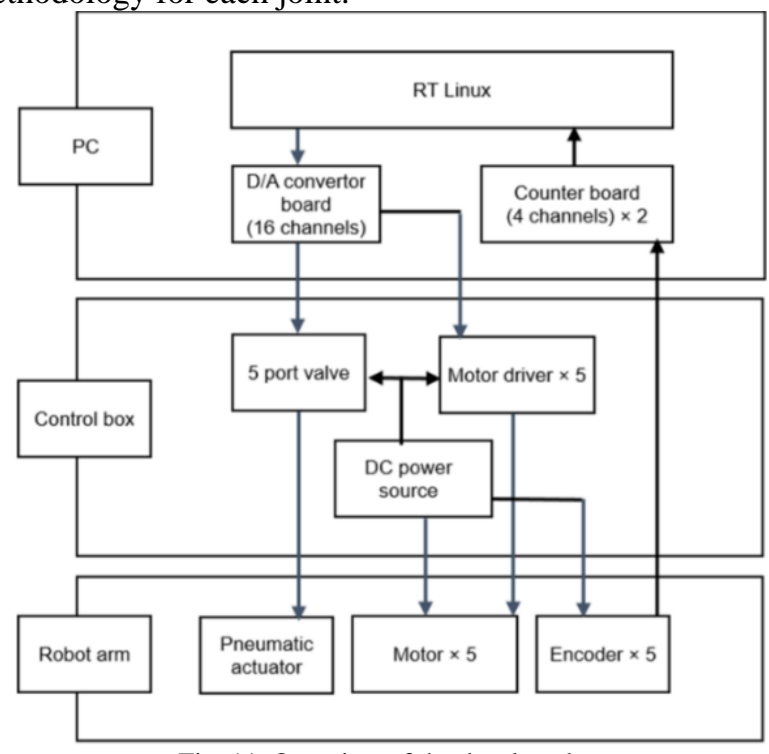

Fig. 11. Overview of the developed arm.

We then devised an algorithm for determining the orbit followed by the arm tip when approaching the asparagus for harvest. If the arm approaches a candidate stem for harvest (Figs. 15 and 16), without making the joint of the wrist crooked, contact will be made with an asparagus stem that is not a candidate for harvest. The arm must bypass the nontarget, and we draw straight lines that connect the asparagus stem and joints $\mathrm{J} 2$ and $\mathrm{J} 4$. We denote those angles as $\alpha$ following the algorithm (Fig. 17), transmit the value of $\alpha$ to the computer of the robot arm, and provide the orbit of the arm in one meaning for certain. When we judge that the orbit of the arm does not come into contact with non-targets in the case of $\alpha=0^{\circ}$, we set $\alpha=0^{\circ}$. In the case the arm touches a non-target asparagus plant, we change the value of $\alpha$ stepwise, such as in the sequence $10^{\circ},-10^{\circ}, 20^{\circ},-20^{\circ}$, within the range of $\pm 90^{\circ}$ to find a suitable value of $\alpha$. In the case that we cannot determine a suitable vale of $\alpha$, we consider that it is not possible to harvest the target stem. In the judgement of whether the arm touches a non-target plant, we define that whether there were any points that mean the coordinates of the asparagus stem's center or not within the yellow-lined

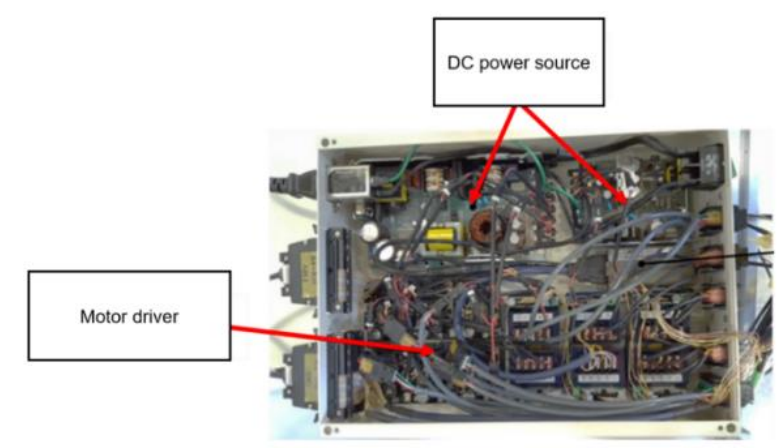

Fig. 12. Control box of the control part.

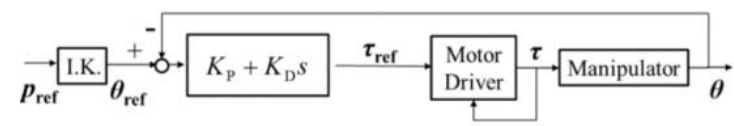

Fig. 13. Block diagram of the control.

We next describe the control side of the robot arm (Fig. 14). The position of the arm is defined as that of the end of the robot arm, where $\alpha$ is defined shown as Fig. 14. We input $\alpha$ to a robot arm system, and calculated data of the arm's orbit in one meaning. We describe the detailed theory for the determination of $\alpha$ later. In this case, because $l 5$ was a constant value of $200 \mathrm{~mm}$, we could determine the position of joint J4 by determining $\alpha$. Furthermore, we determined the relative displacement of the rotation angles of joints $\mathrm{J} 2$ and $\mathrm{J} 3$ and computed the target torque and target angular velocity $q_{\text {ref }}$ for each joint by differentiating the target angle qref of each joint with respect to time (following equations (1)-(3)).

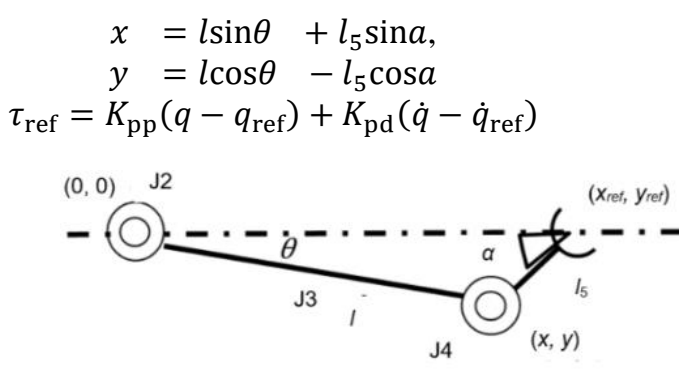

Fig. 14. Control model for the developed robot arm.

rectangle area (Fig. 16), the width of yellow line was d. We determined d to be $120 \mathrm{~mm}$ considering the whole balance for the experiments.

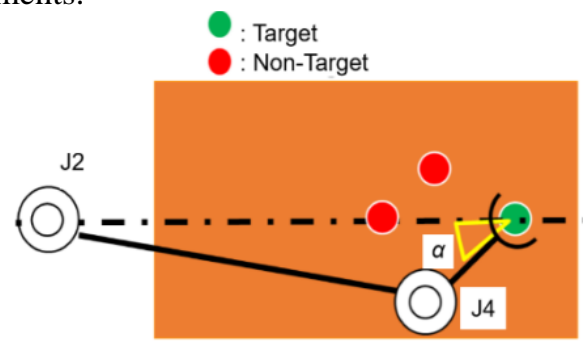

Fig. 15. Approaching a target asparagus stem.

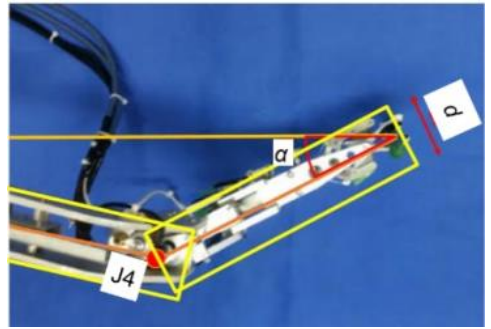

Fig. 16. Configured area in which to detect contact. 


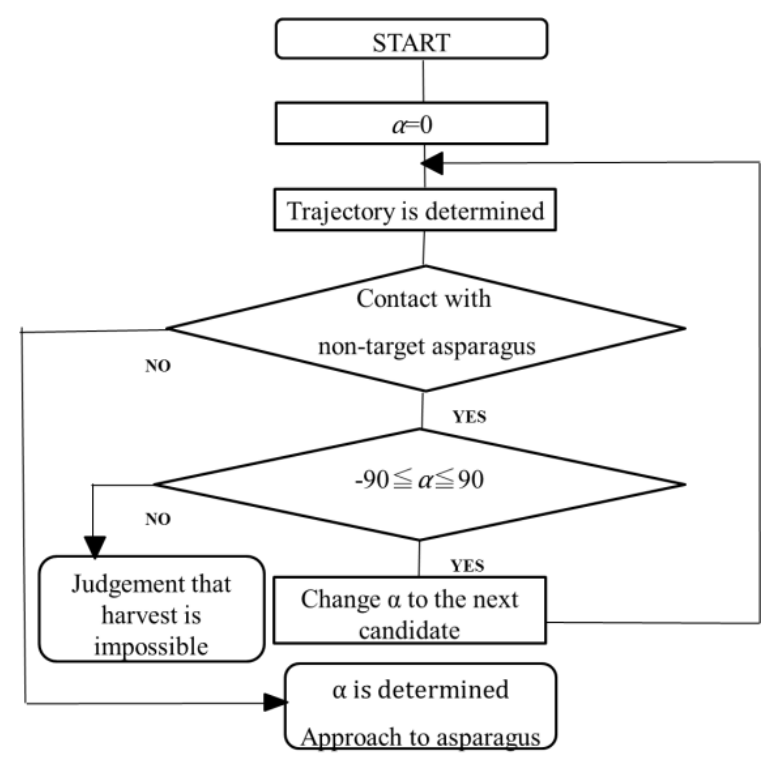

Fig. 17 Algorithm for avoiding asparagus stems that are not appropriate for harvesting.

\section{RESUlTS AND DISCUSSION}

We checked the accuracy of the positioning of the tip (i.e., end) of the robot arm. In the $x-y$ plane, to measure the accuracy of positioning, we set the arm in its standard (default) posture shown in Fig. 2, denoted the coordinates of the tip of the arm as $\mathrm{O}(0,0)$, drove joints $\mathrm{J} 2, \mathrm{~J} 3$, and $\mathrm{J} 4$ in order, and made measurements. We first sent data concerning the target position as a sinusoidal signal to joint $\mathrm{J} 2$ and then sent data signals in the same way to both joints $\mathrm{J} 3$ and J4 successively, thereby controlling the arm. When giving the target displacement to each joint, the effects of other joints were not added. Furthermore, other joints were fixed after advanced preliminary experiments. The coordinates of the arm were measured using equipment for the threedimensional measurement of movement. We judged the equipment was enough precise and comprised a counting system that had a marker for the infrared sensor and recorded three-dimensional data. The root-mean-square accuracy was $0.10 \mathrm{~mm}$. We thus recorded three-dimensional data in real time. We compared the $\mathrm{x}-\mathrm{y}$ coordinates measured using the three-dimensional measurement equipment with the $x-y$ coordinates measured using the encoder. We thereby evaluated whether in the arm, positioning at a tip has made it how much exact. The sampling frequency was set at $1500 \mathrm{~Hz}$, which is sufficient considering the speed of harvest on cultivated land. We fixed a marker for the infrared sensor at the tip of the arm after the experiments and present results at the time a sinusoidal wave signal was sent to joint J2 (Figs. 18 and 19). Errors in the $\mathrm{x}-\mathrm{y}$ coordinate plane were a maximum of $5 \mathrm{~mm}$ when using the encoders. We supposed that the main cause of errors was because of backrushes of the hypoid gear, and the ranges could not be read by the encoders enough. Furthermore, we considered there was error because the hand passed target values. We judged the error ranges as being acceptable because the width of the hand was about $40 \mathrm{~mm}$. Experimental results obtained when a sinusoidal signal was sent to joint $\mathrm{J} 3$ are presented in Fig. 20. The data error of the encoder in the y-direction was a maximum of about $1 \mathrm{~mm}$. Experimental results obtained when sending a sinusoidal signal to joint $\mathrm{J} 4$ are presented in
Figs. 21 and 22. Errors in $x-y$ coordinates of the data recorded by the encoders were within $10 \mathrm{~mm}$. The error is assumed to be due to 1) the inefficient matching of gears and 2) movements of the tip of the arm beyond the area in which encoders could read the movement. Even if 5.0-mm errors for joint $\mathrm{J} 2$ are added to the aforementioned error of $10.0 \mathrm{~mm}$, the maximum error is at most $15.0 \mathrm{~mm}$, which is permitted. We therefore confirm that the error was within a safe range, considering the width of the holding portion at the tip of the arm was $40.0 \mathrm{~mm}$. Through the experiment, we observed and judged that the difference between the position computed with the encoder and the actual position measured with threedimensional measurement equipment was within an acceptable range considering the real situation of harvesting tasks. The aforementioned set of results confirm that the positional accuracy of the tip portion of the arm was appropriate for the aim of the present study.
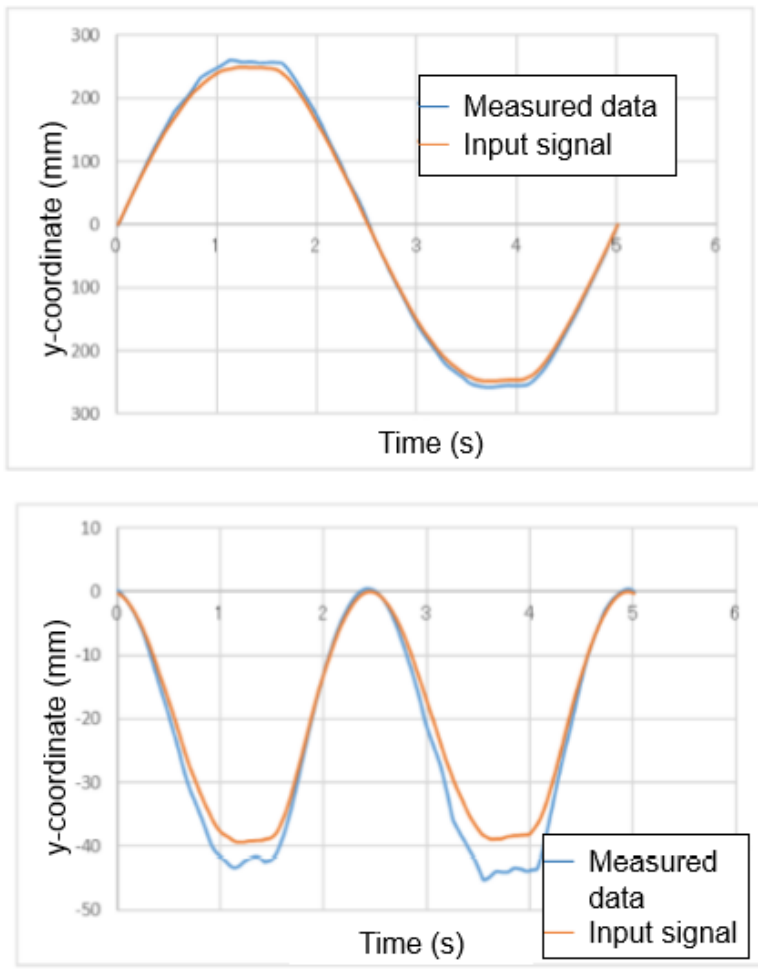

Fig. 18 and 19. $\mathrm{x}-\mathrm{y}$ coordinates of joint $\mathrm{J} 2$. 


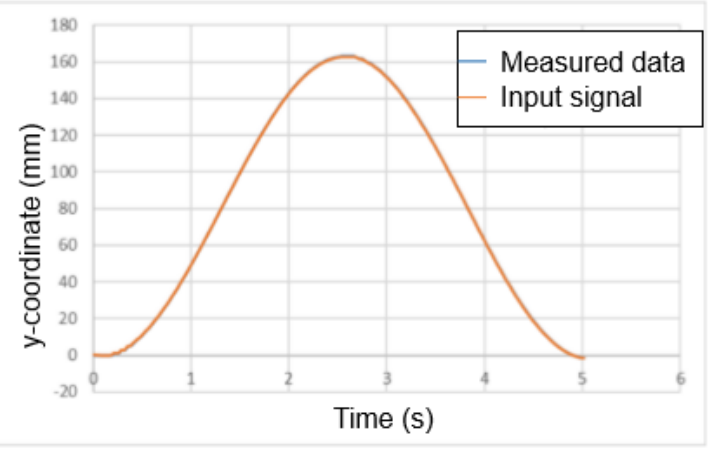

Fig. 20. y-coordinate of joint J3.
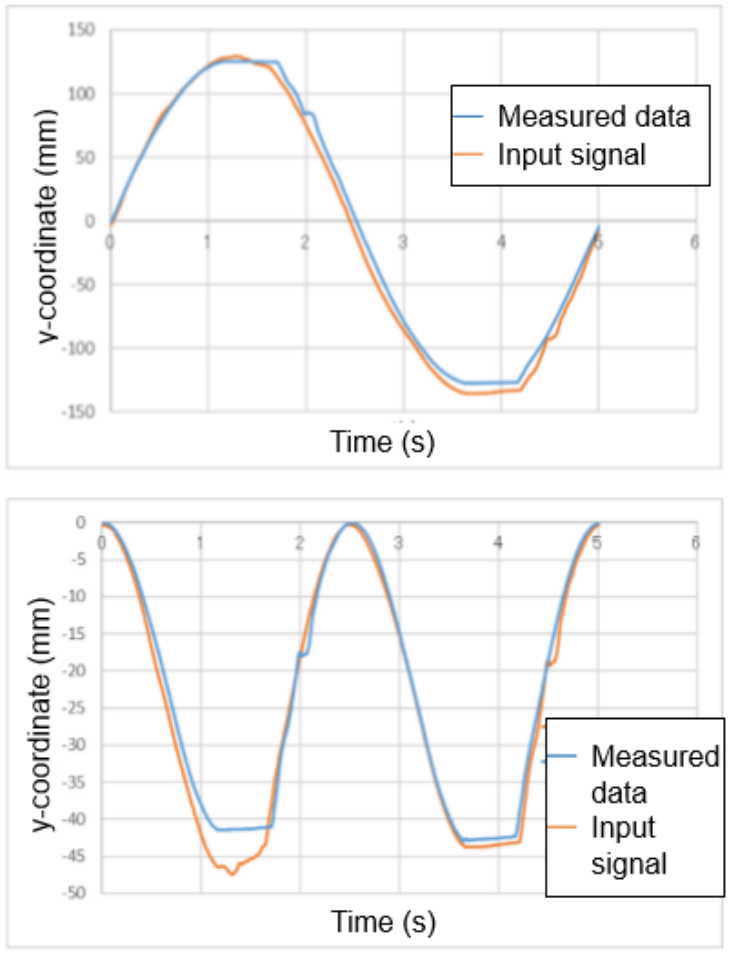

Fig. 21 and 22. $\mathrm{x}-\mathrm{y}$ coordinates of joint $\mathrm{J} 4$.

We confirmed the functions of the robot arm and algorithm in terms of 1) whether the arm could bypass the non-target asparagus and 2) whether the arm could approach the target asparagus. We also checked that the harvesting task became easier as the number of asparagus stems decreased. The number of non-target asparagus plants affects the difficulty of harvesting in itself, and we thus used the density of non-target asparagus stems per $\mathrm{m} 2$ as an indicator of the degree of difficulty of harvesting. Furthermore, we originally constructed imitation stems and set their coordinates (Figs. 23 and 24). In the experiment, we considered the sizes of common actual troughs and arranged the positions for harvesting as $(0,200)$ and $(0,300)$. We set the size of the robot arm and hand according to the coordinates of the imitation trough. The $\mathrm{x}$-coordinate of the orbit that the arm could take was limited by the algorithm because, at joint J4, the length of the hand part was $200 \mathrm{~mm}$. Similarly, because the algorithm does not gather a harvest from the back for harvest, $y$-coordinates larger than that of the candidates for harvest cannot exist on the orbit. Therefore, the asparagus for un-gathering a harvest is required. Arranged at the position that can become an obstacle in harvesting. In consideration of the above, non-target objects were arranged randomly in the area $(-200 \leq \mathrm{x} \leq 200,0 \leq \mathrm{y} \leq \mathrm{y}$-coordinate of the target stem; i.e., the area enclosed by the light-green line in Fig. 23). In the 10 experimental runs, the density of non-target stems was set at $0,25,50,75$, and 100 for each set of target stem coordinates, namely $(0,200)$ and $(0,300)$, giving 10 patterns in total (Fig. 24). In the MATLAB programming environment, for the same settings, and we carried out 1000 simulations (Figs. 25 and 26) because we had difficulties in conducting enough runs of the aforementioned experiments and because we wished to compare our real experiment data set with simulation data. In both the real trials and MATLAB simulation, we judged a case that the system harvested the target stem without touching non-target stems as a success, and summarized the data using the success ratio.

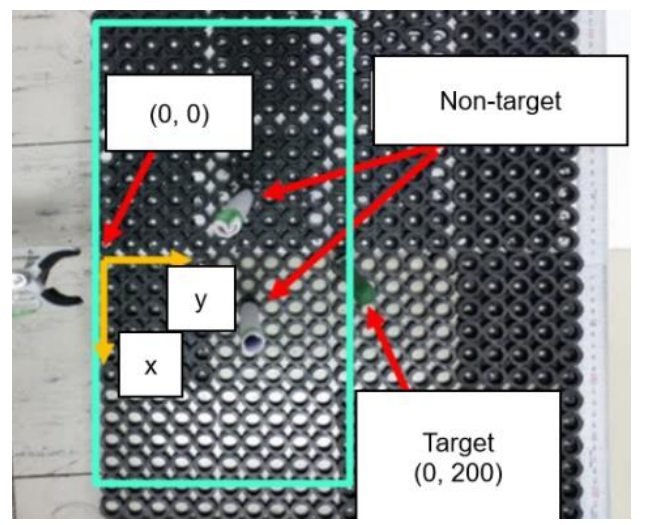

Fig. 23. Indoor experimental situation using the developed robot arm.

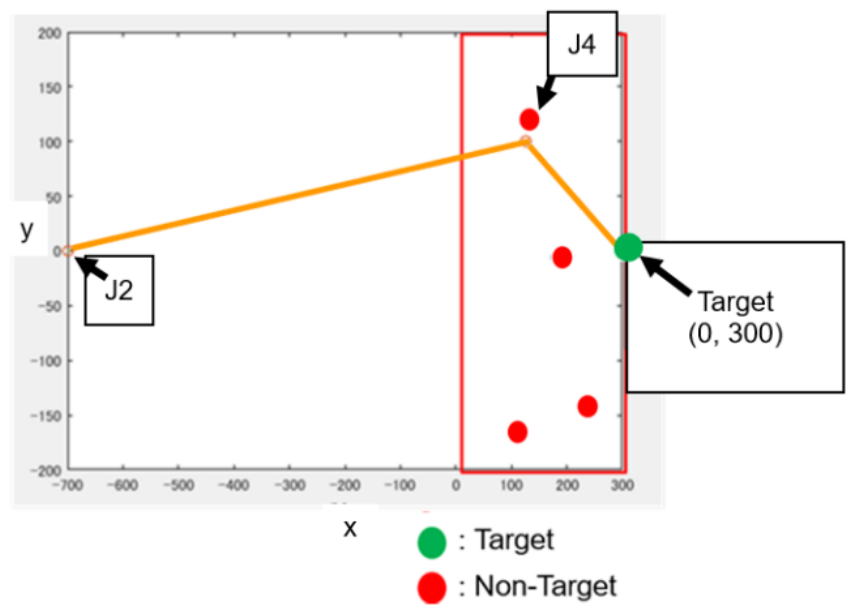

Fig. 24. Indoor experimental situation.

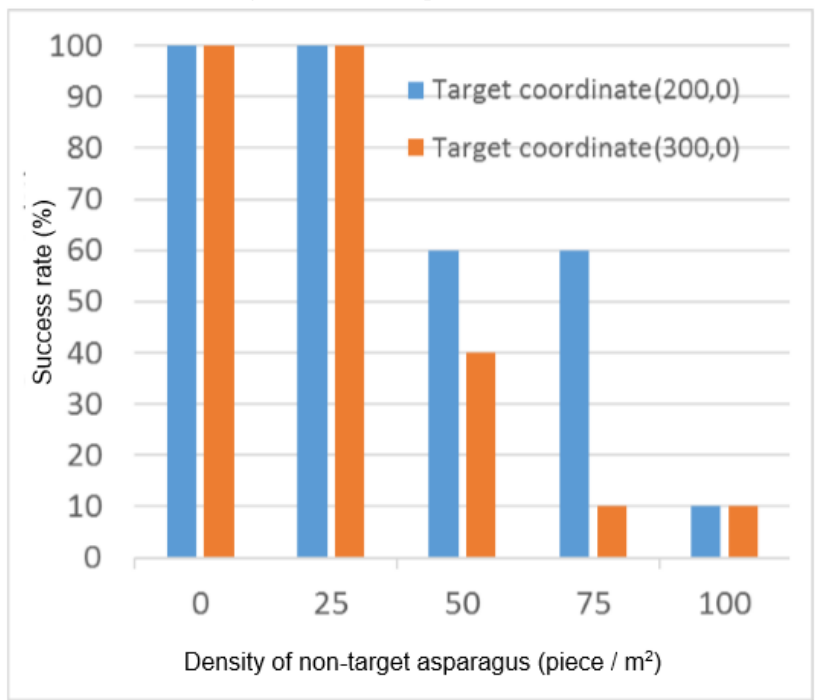

Fig. 25. Results of the indoor experiment using the developed robot arm. 


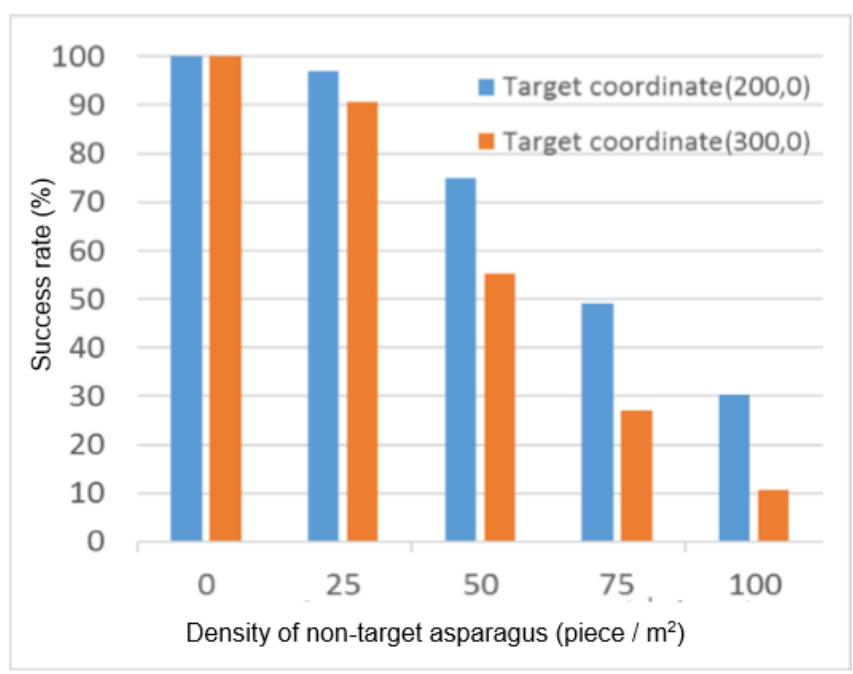

Fig. 26. Results of the indoor experiment obtained by simulation using an original program written and executed in MATLAB.

In the experiment, the success ratio exceeded $90 \%$ when the density of non-target plants was 25 stems per m2. A comparison of results for coordinates of the target asparagus of $(200,0)$ and $(300,0)$ confirms that the arm must avoid more non-target stems and the possibility of success decreases as the distance to the target stem increases. We obtained similar results in the aforementioned MATLABbased simulations. When the density of non-target asparagus exceeded 50 stems per $\mathrm{m} 2$, however, the success ratio was much lower. In reality, during the hottest time in summer in Kantou area, Japan, the density is likely to be 50 stems per $\mathrm{m} 2$, and we need to improve the success rate at this density. Here we present the promising utility of the system. We present an example pattern that the system could not harvest in Fig. 27. When the passage was narrower than $120 \mathrm{~mm}$, the system automatically judged the situation as being inappropriate for harvesting, quit the current phase, and progressed to the next phase. With the arm developed at this time, the harvest cannot be gathered in this environment. We therefore needed to reduce the width of the hand part and to set d smaller than $120 \mathrm{~mm}$. For instance, when we performed simulations for $\mathrm{d}=90 \mathrm{~mm}$ and a density of non-target asparagus of 50 stems per $\mathrm{m} 2$ (Fig. 28), the success ratio was around $90 \%$, which is a remarkable improvement.

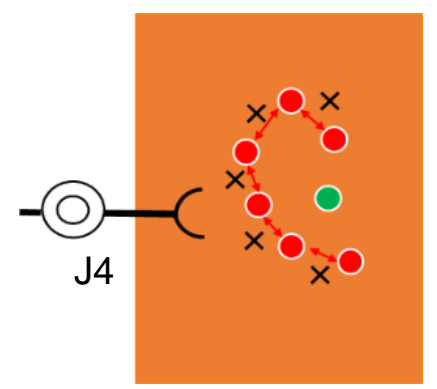

Fig. 27. Example of a situation of failed harvesting.

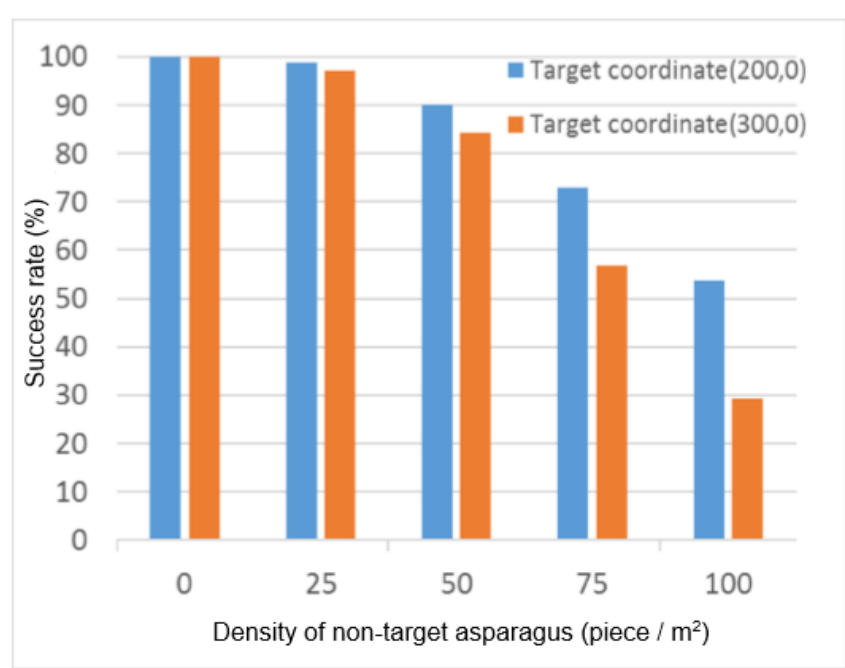

Figure. 28 Simulation results for $d=90 \mathrm{~mm}$

We conducted verification experiments for the developed arm on actual cultivated land (Fig. 29). We chose the cultivated lands of a farmhouse in Tochigi Prefecture, Japan as the test sites. When using the system on cultivated land, the hard portion of the control system carried out the cover so that dust soared from the soil and the leaves of asparagus might be needed in a control box and a personal computer and might not be crowded. An independence run function did not stick at a present stage, however movement over irregular ground was difficult for the system. We therefore experimented on the lower part of the arm foundation by covering with a specific board to protect it. Moreover, because the experiment was conducted at a time when there were few asparagus plants, we did not need to bypass nontarget asparagus stems, and carried out the experiments without using joint J4. Beforehand, we started the employment experiment, after measuring the coordinates of the asparagus positions. At this time, we measured the distance and angle of the location of the asparagus from the starting point of the robot arm with a tape measure and protractor, and we then computed the $\mathrm{x}-\mathrm{y}$ coordinates on the usual plane using trigonometric functions. We first measured the position coordinates of the asparagus and approached the asparagus of one flat knot. We then operated the hand part and performed maintenance and cutting of the asparagus. Additionally, we went that even the basket for harvest was about asparagus and stored in the basket. Finally, as the development version, we approached asparagus of two flat knots and three flat knots continuously and carried out a similar experiment of gathering the harvest. We used the results to check that a harvest could be gathered satisfactorily when the coordinates of asparagus are known on actual farmland, and we judged that we could harvest the other two asparaguses (second and third stems) as the objects of continuous harvest in the experiment. 


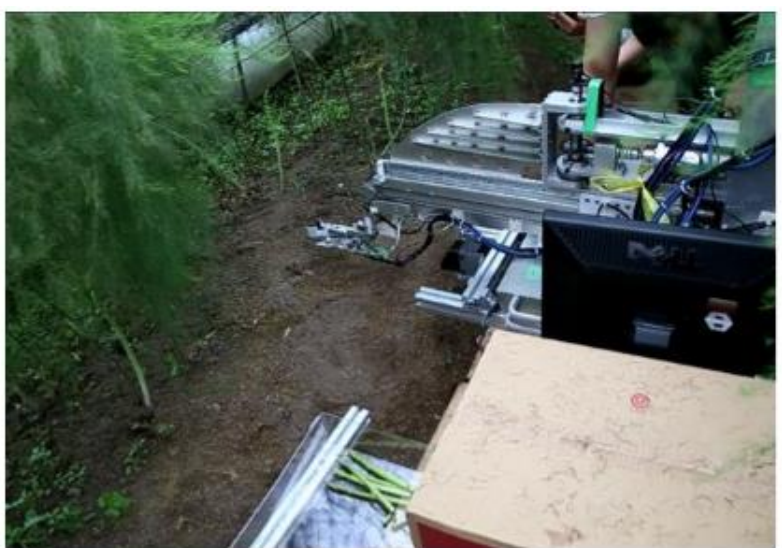

(a) Start

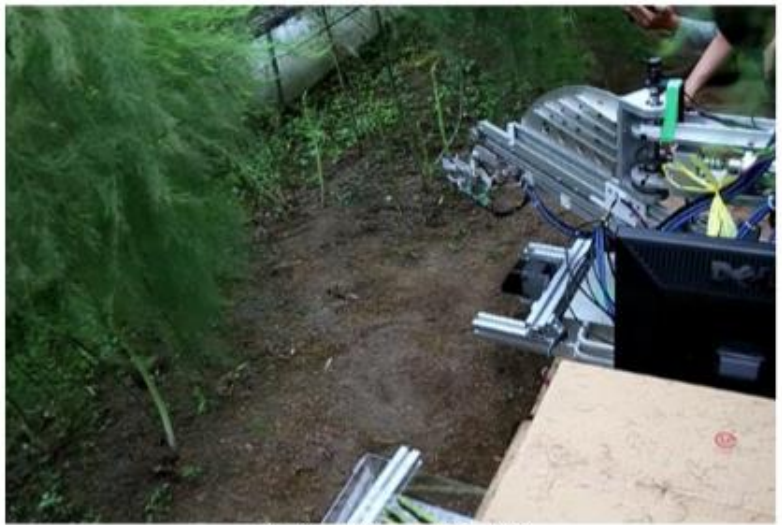

(b) Rotation of joint $\mathrm{J} 2$

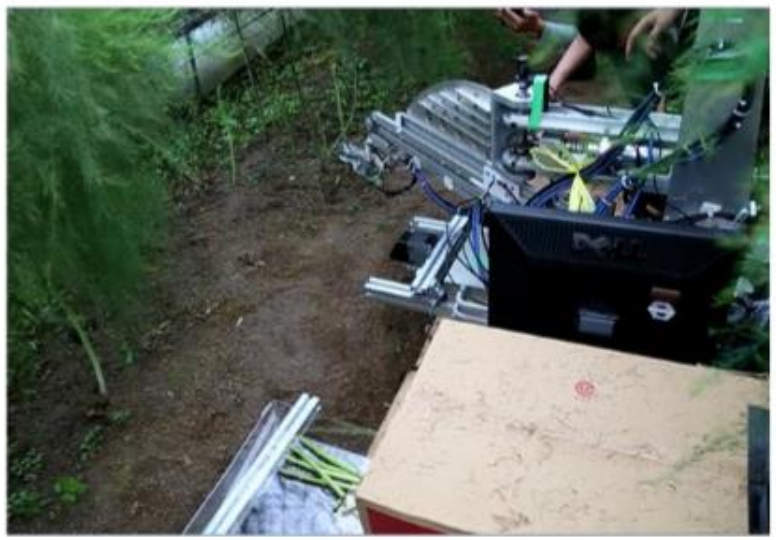

(c) Extension of joint J3, gripping the stem and cutting it off

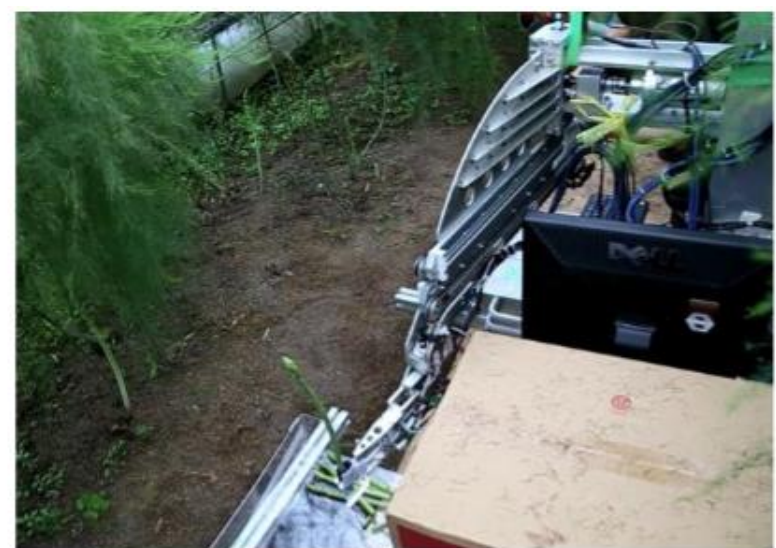

(d) Curling of joint $\mathrm{J} 3$, rotation of joint $\mathrm{J} 2$, and lifting of joint $\mathrm{J} 1$

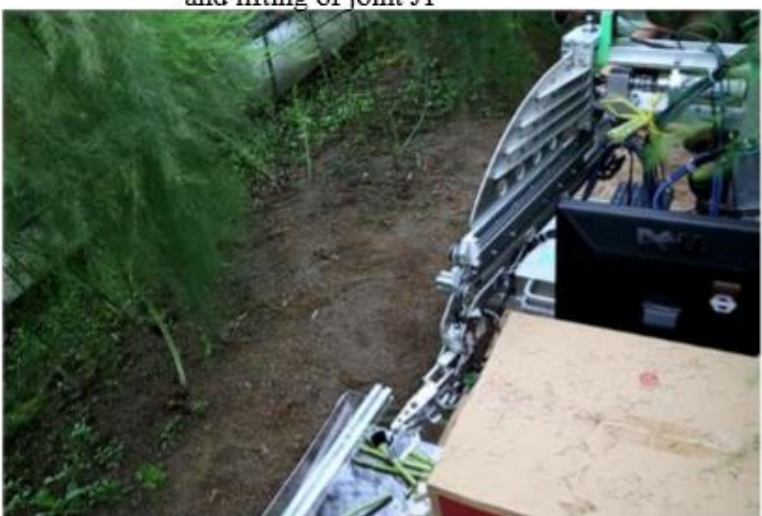

(e) Releasing the cut stem

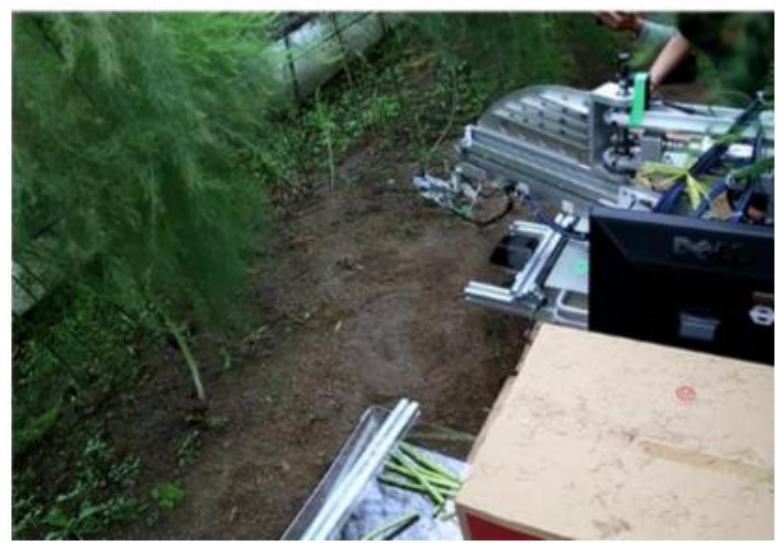

(f) Approaching the next stem

Fig. 29. Actual motions of our developed robotic arm operating on common farmland.

\section{CONCLUSION AND FUtURE WORK}

We developed an arm robot for the automatic harvesting of asparagus and conducted a verification experiment on actual cultivated farmland with the developed system. The system performed as intended, without a need to change the experimental situation of passages on the farmland and agricultural products. First, we gathered and analyzed existing designs and manufactures thinking of our system's developments, social concepts and attributes. Second, considering future actual driving, we decided the mechanisms of the robot arm for approaching, grasping, cutting, and throwing stems of asparagus such that the arm does not come into contact with (i.e., tear) mesh nets protecting the plants from birds, insects, and stones on the upper side of the asparagus. Third, we bypassed non-target asparagus stems through specific design and construction of the system. The developed system could cut and gather asparagus stems without damaging the stems and touching the non-target stems. We adopted a hand part driven by air pressure that could hold the object of harvest more softly than the past existing similar systems. We described in detail the composition and control method of the arm. Specifically, we explained 1) the composition of the system, 2) the inverse kinematics, 3) the block diagram, and 4) the algorithm for avoiding non-target stems and for approaching selected stems. In addition, we carried out an indoor evaluation experiment of the developed arm, and presented results and 
considerations. In an experiment on the accuracy of the mechanism that determines the position of the tip of the robot arm, we checked that the position of the tip followed the theoretical position in general and that the accuracy of positioning was sufficient for the system to harvest asparagus. Furthermore, we carried out an outdoor experiment on the density limit at the time of harvesting asparagus on cultivated land. We achieved a harvest success rate of $100 \%$ when the density of non-target asparagus was 25 stems per $\mathrm{m} 2$, showing the potential of the system, but achieved a lower success rate at a higher density of non-target asparagus. Overall, the operation of the entire system on actual cultivated land was successful.

\section{FUTURE WORK}

We plan to study the following in future work.

(1) Development and installment of a visual data analysis function

When we harvested asparagus stems automatically, we needed to decide which stems should be harvested and to measure the coordinates of target stems and other stems before execution. The system was used outdoors and required a camera with a telephoto lens to 1 meter beyond. We attempted to use a depth-map (distance-measurement) sensor (MEMS 3D laser sensor FX 10, Nippon Signal Inc., Japan) having an infrared laser. However, when we measured the positional coordinates of a target asparagus, we observed errors of about $100 \mathrm{~mm}$ several times. In other words, in making measurements using a common infrared laser sensor, we confirmed that there were strict limitations concerning the accuracy, and certainly, there have been social needs to add functions to approaches the hand(s) using a hand camera to asparagus stems more precisely. Moreover, we supposed that, by introducing such a hand camera, we can rectify the slight error in positioning at the tip of the arm in the trials.

(2) Miniaturization of the arm

Because experiments were conducted on actual cultivated lands in the present study, when the present robot arm was installed, there was hardly a crevice between the system and the trough. In other words, when introducing the system to an actual agricultural site, it was apparent that the size of the system needed to be reconsidered. Moreover, we need to examine the problem of the weight of the system. It became clear that the weight was a large burden to the user in the verification experiment conducted on actual cultivated land. In addition, if the system is to be used in the future, it will be hard work for an agricultural company having a large proportion of elderly staff to move the system to and from cultivated fields. We will therefore endeavor to make the robot arm smaller and to reduce the weight. Moreover, the steep increase in the rate of the asparagus that can gather a harvest trusted us by making thickness of a robot arm thin from the simulation result mentioned above, and it is important to design the arm as thin as possible.

(3) Development of independently running functions

So that the developed system can harvest asparagus automatically, we must provide the system with independently running functions. We guessed that the system was expected to be completed in the meaning of our first phase of the provision for society with installing auxiliary factors: 1) function(s) for automatically running on irregular ground, 2) a function for self-positioning of the system base (i.e., body) both inside and outside an agricultural greenhouse using, for example, the Global Positioning System, and 3) reduction of the number of staff and the cost at an agricultural worksite. In addition to the aforementioned functions, we would like to add functions for automatic movement from a passage between two ridges to another passage, not only movement along a passage. Furthermore, we wish to attach a function for automatic movement to a warehouse to unload harvested asparagus or to change the filled basket to a new basket, because we regard the part of an independence run as a portion with one flexibility. We also wish to add a function that prevents collisions with people, and a function that presents the fall of the robot arm. In addition, to increase the efficiency of harvesting, we must develop smaller versions of the arm.

\section{REFERENCES}

[1] P. Abhishesh, B. S. Ryuh, Y. S. Oh, H. J. Moon, and R. Akanksha, "Multipurpose Agricultural Robot Platform: Conceptual Design of Control System Software for Autonomous Driving and Agricultural Operations Using Programmable Logic Controller," International Journal of Mechanical, Aerospace, Industrial, Mechatronic and Manufacturing Engineering, vol. 11, no. 3, pp. 496-500, January 2017.

[2] S. Arima, N. Kondo, Y. Yagi, M. Monta, and Y. Yoshida, "Harvesting robot for strawberry grown on table top culture," Journal of SHITA, vo. 13, no. 3, pp. 159-166, January 2001.

[3] S. Arima, S. Shibusawa, N. Kondo, and J. Yamashita, "Traceability based on multi-operation robot; information from spraying, harvesting and grading operation robot," Proceedings of International Conference on IEEE/ASME 2003, vol. 2, pp. 1204-1209, 2003.

[4] S. Arima, N. Kondo, and M. Monta, "Strawberry Harvesting Robot on Table-top Culture," Proceedings of ASAE Annual Meeting 2004, pp. 1, 2004.

[5] M. Ayamura, "Experiment of running operation and harvesting motions related to asparagus harvesting robot in farmland," Proceedings of IEEE/SICE International Symposium on System Integration: SI2013, pp. 2671-2674, 2013.

[6] C. W. Bac, E. J. Henten, J. Hemming, and Y. Edan, "Harvesting Robots for High-value Crops: State-of-the-art Review and Challenges Ahead," Journal of Field Robotics, vol. 31, no. 6, pp. 888-911, 2014.

[7] T. Bak, and H. Jakobsen, "Agricultural robotic platform with four wheel steering for weed detection," Biosystems Engineering, vol. 87, no. 2, pp. 125-136, 2004

[8] A. Bechar, and C. Vigneault, "Agricultural robots for field operations: Concepts and components," Biosystems Engineering, vol. 149, pp. 94 $111,2016$.

[9] A. Bechar, and C. Vigneault, "Agricultural robots for field operations. Part 2: Operations and systems," Biosystems Engineering, vol. 153, pp. 110-128, 2017.

[10] V. Bloch, A. Degani, and A. Bechar, "Task characterization and classification for robotic manipulator optimal design in precision agriculture," Precision agriculture'15, pp. 247-257.

[11] E. A. Bobeck, D. K. Combs, and M. E. Cook, "Introductory animal science-based instruction influences attitudes on animal agriculture issues," Journal of Animal Science, vol. 92, no. 2, pp. 856-864, 2014.

[12] F. A. Cheein, D. Herrera, J. Gimenez, R. Carelli, M. Torres-Torriti, J. R. Rosell-Polo, and J. Arnó, "Human-robot interaction in precision agriculture: Sharing the workspace with service units," Proceedings of 2015 IEEE International Conference on Industrial Technology (ICIT), pp. 289-295, 2015.

[13] M. D. Coley, W. J. Warner, K. S. Stair, J. L. Flowers, and D. B. Croom, "Technology Usage of Tennessee Agriculture Teachers," Journal of Agricultural Education, vol. 56, no. 3, pp. 35-51, 2015.

[14] S. Cubero, S. Alegre, N. Aleixos, and J. Blasco, "Computer vision system for individual fruit inspection during harvesting on mobile platforms," Precision agriculture, vol. 15, pp. 547-552, 2015.

[15] A. English, P. Ross, and D. Ball, "Vision based guidance for robot navigation in agriculture," Proceedings of 2014 IEEE International Conference on Robotics and Automation (ICRA), pp. 1693-1698, 2014.

[16] Y. Fujii, T. Nanseki, H. Kobayashi, and T. Kojima. "The characteristics of expert know-how in agricultural planning on large-scale paddy field 
farms: a case study of a corporate farm in Shiga prefecture," Agricultural Information Research, vol. 22, no. 3, pp. 142-158, 2013.

[17] T. Grift, Q. Zhang, N. Kondo, and K. C. Ting, "A review of automation and robotics for the bioindustry," Journal of Biomechatronics Engineering, vol. 1, no. 1, pp.1, January 2008

[18] M. Mann, B. Zion, I. Shmulevich, and D. Rubinstein, "Determination of robotic melon harvesting efficiency: a probabilistic approach,' International Journal of Production Research, vol. 54, no. 11, pp. 3216-3228, 2016.

[19] S. S. Mehta, and T. F. Burks, "Vision-based control of robotic manipulator for citrus harvesting," Computers and Electronics in Agriculture, vol. 102, pp. 146-158, January 2014.

[20] Y. Morio, T. Shoji, and K. Murakami, "Working motion templates for detecting agricultural worker behaviors," Engineering in Agriculture, Environment and Food, vol. 9, no. 4, pp. 297-304, 2016.

[21] S. Muhammad, S. Zora, and S. K. Ahmad. "Delayed harvest and cold storage period influence ethylene production, fruit firmness and quality of 'Cripps Pink' apple. International Journal of Food Science and Technology, vol. 2011, no. 46, pp. 2520-2529, January 2011.

[22] S. Nakayama, M. Ohno, H. Hori, M. Tanaka, N. Toda, and M. Hirafuji, "Research on the Requirements for Field Server, and Study of a Design and Manufacturing Method to Mass-produce Field Server. Agricultural Information Research, vol. 23, no. 1, pp. 29-37, January 2014

[23] T. Nanseki, S. Takeuchi, and Y. Shinozaki, "Business development, ICT use, and personal training in agricultural corporations: an analysis of nationwide questionnaire survey. Agricultural Information Research, vol. 22, no. 3, pp. 159-173, 2013.

[24] F. Y. Narvaez, G. Reina, M. Torres-Torriti, G. Kantor, and F. A. Cheein, "A Survey of Ranging and Imaging Techniques for Precision Agriculture Phenotyping. IEEE/ASME Transactions on Mechatronics, vol. 22, no. 6, pp. 2428-2439, 2017.

[25] Panasonic Inc. "Robots living with human. Official introduction of products. http://news.panasonic.com/jp/stories/2016/45398.htm Accessed 25 September 2016.

[26] S. M. Pedersen, S. Fountas, H. Have, and B. S. Blackmore, "Agricultural robots-system analysis and economic feasibility," Precision agriculture, vol. 7, no. 4, pp. 295-308, 2006.

[27] M. Sekine, K. Sugimori, and W. Yu, "Research of Shoulder Prostheses Based on Spatial Accessibility Evaluation - Designing and Prototyping a Small Pneumatic Actuator Driven Parallel Link Arm -," Life Support, vol. 2012, no. 24, pp. 170-174, 2012.

[28] Shibuya Seiki Co., Ltd. (2013) "Stable robot for strawberry harvesting combined with circulative moving planting system," Publications of National Agriculture and Food Research Organization. http://www.naro.affrc.go.jp/project/results/laboratory/brain/2013/13_ 087.html. Accessed 31 December 2013

[29] A. Shinjo, and M. Kudo, "The practical use of IT in agriculture: the movement into high-value-added crops and integrated solutions," The Journal of the Institute of Electronics, Information, and Communication Engineers, vol. 96, no. 4, pp. 280-285, 2013.

[30] A. Silwal, J. R. Davidson, M. Karkee, C. Mo, Q. Zhang, and K. Lewis, "Design, integration, and field evaluation of a robotic apple harvester," Journal of Field Robotics, vol. 34, no.6, pp. 1140-1159, 2017.

[31] L. N. Smith, W. Zhang, M. F.Hansen, I. J. Hales, and M. L. Smith, "Innovative 3D and 2D machine vision methods for analysis of plants and crops in the field," Computers in Industry, vol. 97, pp. 122-131, 2018.

[32] Squse Inc. "Tomato harvesting robot. Official introduction of products," http://www.squse.co.jp/news/detail.php?id=205. Accessed 31 October 2014

[33] Y. Taguchi, "Development of totally Automatic harvesting robot. Publications of University of Nagasaki,", https://www.pref.nagasaki.jp/shared/uploads/2013/09/1380349099.pd f. Accessed 31 December 2013.

[34] V. F. Tejada, M. F. Stoelen, K. Kusnierek, N. Heiberg, and A. Korsaeth, "Proof-of-concept robot platform for exploring automated harvesting of sugar snap peas," Precision Agriculture, vol. 18, no. 6, pp. 952-972, 2017.

[35] A. C. Thoron, and S. E. Burleson, "Students' Perceptions of Agriscience when Taught Through Inquiry-Based Instruction," Journal of Agricultural Education, vol. 55, no. 1, pp. 66-75, 2014.

[36] N. Tsujiuchi, A. Ito, Y. Nakaie, and N. Katayama, "360 Vibration Characteristics Evaluation and Vibration Reduction of 5-Axis ScottRussell Robot Arm. Proceedings of Dynamics and Design Conference: $D$ and D 2014," vol. 360, pp. 1-13, 2014.

[37] R. Vidoni, R. Gallo, G. Ristorto, G. Carabin, F. Mazzetto, L. Scalera, and A. Gasparetto, "An Agricultural Mobile Robot Prototype for Proximal Sensing and Precision Farming," Proceedings of ASME (American Society of Mechanical Engineers) 2017 International
Mechanical Engineering Congress and Expsition, V04AT05A057, pp. 1-7, January 2017.

[38] P. A. Witt, J. D. Ulmer, S. Burris, T. Brashears, and H. Burley, "A Comparison of Student Engaged Time in Agriculture Instruction," Journal of Agricultural Education, vol. 55, no. 2, pp. 16-32, 2014

[39] B. Yang, N. Hanajima, A. Yamamoto, M. Ayamura, and J. Dai, "Pathgenerating regulator along a straight passage for two-wheeled mobile robots," Proceedings of 2013 IEEE/RSJ International Conference on Intelligent Robots and Systems (IROS), pp. 4837-4844, April 2013.

[40] P. Zhao, T. Chen, W. Wang, and F. Chen, "Research on the Agricultural Skills Training Based on the Motion-Sensing Technology of the Leap Motion," Computer and Computing Technologies in Agriculture, vol. 9, pp. 277-286, April 2016.

[41] Y. Zhao, L. Gong, Y. Huang, and C. Liu, "A review of key techniques of vision-based control for harvesting robot," Computers and Electronics in Agriculture, vol. 127, pp. 311-323, 2016.

[42] A. Zujevs, V. Osadcuks, and P. Ahrendt, "Trends in robotic sensor technologies for fruit harvesting: 2010-2015," Procedia Computer Science, vol. 77, pp. 227-233, January 2015.

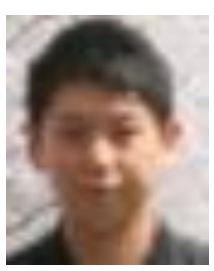

Yuki FUNAMI Place of birth: Kanagawa Pref. Japan. 1994. M.S. in Engineering, Tokyo Institute of Technology, 2018, Meguro-ku, Tokyo, Japan. B.A in Engineering, Yokohama National University, 2014, Yoohama, Japan.

Career: Engineer.

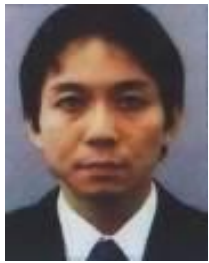

Shinji KAWAKURA Place of birth: Toyama Pref., Japan. Date of birth: July 14, 1978. Ph.D. in Environmentology, University of Tokyo, 2015, Bunkyo-ku, Tokyo, Japan. B.A. in Control System Engineering, Tokyo Institute of Technology, 2003, Meguro-ku, Tokyo, Japan. M.A. in Human-Factor Engineering, Tokyo Institute of Technology, 2005, Meguro-ku, Tokyo, Japan.

Career: Systems engineering, research for private companies.

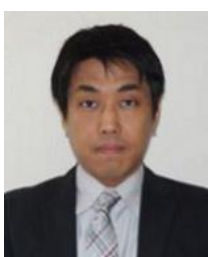

Kotaro TADANO Place of birth: Hokkaido, Japan. Date of birth: 1981. Ph.D. in Engineering, Tokyo Institute of Technology, 2007, Meguro-ku, Tokyo, Japan. B.A in 2003, Tokyo Institute of Technology, Meguro-ku, Tokyo, Japan. M.A in 2005, Tokyo Institute of Technology, , Meguro$\mathrm{ku}$, Tokyo, Japan.

Career: Associate professor at Tokyo Institute of Technology. 